\title{
LÉXICO, IDEOLOGIA E A HISTORIOGRAFIA LINGÜÍSTICA DO SÉCULO DAS IDENTIDADES
}

\author{
Olga Coelho*
}

\section{Introdução}

$\mathrm{O}$ trabalho em historiografia da lingüística leva em conta diferentes dimensões dos processos de produção de conhecimento, entre as quais estão a dos temas ou problemas em torno dos quais essa produção foi desenvolvida; a dos sujeitos (actantes) que lidam com tais problemas e podem cooperar ou rivalizar entre si; a dimensão cronológica, que permite acompanhar eventos marcados pelas atividades dos sujeitos; a da metalinguagem, que envolve a relação dos sujeitos com os temas/problemas tanto quanto a do historiógrafo com respeito ao passado (cf. Swiggers, 1990), para citar apenas algumas.

Considerada a diversidade de perspectivas geradas a partir do privilégio concedido a algumas dessas dimensões, entende-se prontamente que a história da produção do conhecimento lingüístico possa ser reconstruída de diferentes modos, que lancem maior ou menor luz sobre tais variáveis e venham a caracterizá-

* Universidade Presbiteriana Mackenzie - São Paulo. 
las distintamente. Mais do que isso, entende-se que há mais de uma história possível e que o valor daquela que se advoga para um período depende da boa costura dos elementos selecionados para explicá-lo.

Assim, por exemplo, numa historiografia dirigida a um tema, a ênfase às outras dimensões terá sua medida estipulada pela sua relevância; ou seja, a recorrência a dados biográficos, interpessoais, socioeconômicos, políticos, ideológicos, metadescritivos, será determinada pela sua capacidade de ajudar a esclarecer o problema sob análise. Esses dados serão, pois, mais ou menos interessantes conforme o papel que tenham desempenhado para a configuração do conhecimento lingüístico em foco.

Nesse sentido, lidar com alguns temas exigirá maior investimento na consideração da rede de relações entre aspectos internos (problemas, metalinguagem, métodos) e externos (agentes, eventos, contexto).

Neste texto, exemplifica-se como certos temas lingüísticos ganham sentido histórico mais coerente quando relacionados a aspectos de seu processo de elaboração e do contexto que lhe deu ensejo.

Trata-se de uma análise bastante sumária, cujo objetivo é demonstrar que os dados arrolados pelo historiógrafo devem permitir a estruturação de alguma espécie de teia explicativa para o problema investigado, em vez de apenas reunir nomes, datas, títulos de obras, eventos.

O problema a ser considerado é o da autonomia do português do Brasil, tal como formulado por estudiosos da linguagem do século XIX.

São analisados verbetes de vocabulários e dicionários e trechos de artigos publicados entre 1852 e 1890. As fontes consideradas são o Vocabulário brazileiro para servir de complemento aos dicionários de língua portuguesa (1853), de Braz da Costa Rubim (1817-1870), o Diccionario de vocábulos brazileiros (1889), de Henrique de Beaurepaire Rohan (1812-1894), o Diccionario brazileiro de lingua portugueza (1875-1888) e os Estudos lexicográficos do dialecto brazileiro (1874-1890), de Antônio Joaquim de Macedo Soares (18381905).

\section{Alguns dados contextuais}

Debates acerca das chamadas línguas nacionais são uma espécie de lugar-comum nos momentos em que há alguma (re)definição de estatuto político dos povos. Para citar dois exemplos, em toda a América, nas nações que se 
tornaram independentes durante o século XIX, houve uma busca de índices lingüísticos dessa emancipação política, assim como, nos diferentes momentos de organização dos estados europeus, índices lingüísticos de uma identidade particular para os povos foram buscados.

O Brasil não escapou a essa tendência: o grau de autonomia da modalidade de língua portuguesa utilizada no país foi tema de intensas e recorrentes discussões durante os anos 1800 e assumiu, durante o Segundo Reinado (1841-1889), uma fisionomia bastante particular.

De acordo com Schwarcz (1999, p. 22), o Segundo Reinado corresponde a um período de instauração de um novo modelo de nacionalismo no Brasil. Entendia-se que apenas nesse momento em que o país passava a ser dirigido por um líder moderno e brasileiro (d. Pedro II foi o primeiro governante nascido em solo nacional), e , além disso, afeito a ciências, tecnologias e artes, o Estado estaria fortalecido, e o território passaria a constituir, de fato, uma nação. Daí que tenha ocorrido um esforço por parte do próprio Império para organizar os símbolos nacionais e fixar a nossa nacionalidade.

Ao que parece, os dicionários de língua brasileira foram produzidos com a intenção de integrar esse movimento de organização dos símbolos do país (Coelho, 2000) e de consolidação das nossas singularidades. Ao menos, é o que nos fazem crer certos trechos de tais obras, como o seguinte:

\begin{abstract}
(A)
...e, por dezenas de palavras que receberam [os guarani e os tupi] dos invasores, lhes deram milhares! São, principalmente, essas novidades indígenas que fazem do castelhano e do português da América uma língua assaz diferente do castelhano e do português da Europa. É por aí, mais do que pelas instituições políticas, que o Brasil e as repúblicas espanholas vão firmando sua individualidade, sua independência, sua nacionalidade. (Soares, 1942 , nota 44, p. 229, sem grifos no original)
\end{abstract}

Tais trabalhos realizados com o léxico, dessa forma, encerram o pressuposto de que, aquilo que, no âmbito lingüístico, melhor representaria a nova nação - o léxico - mereceria ser acrescentado ao dicionário "total" da língua portuguesa (proposta de Braz da Costa Rubim e de Henrique de Beaurepaire 
Rohan) ou, idealmente, constituir monumentos lexicográficos autônomos e nacionais, de modo a "firmar" a nossa individualidade (Macedo Soares).

Para esses autores, tornava-se necessário conceder aos chamados brasileirismos títulos de constituintes legítimos da língua, difundi-los entre a população e, dessa forma, alterar a tendência brasileira de enxergar o modo português de expressão como guia:

(B)

Já é tempo dos brazileiros escreverem como se falla no Brazil, e não como se escreve em Portugal. (Soares, 1954, p. 1)

\section{Aspectos do tratamento do tema no período}

É certo que não é possível tratar todas essas obras de modo uniforme, até pelo período que separa, por exemplo, o texto de Rubim, de 1853, do de Rohan, produzido no final do século.

Contudo, algumas sínteses importantes podem ser feitas, e essas sínteses englobam não só essas obras, mas também outras dedicadas à exploração do tema durante o Segundo Reinado, período em que instituições acadêmicas como o Instituto Histórico e Geográfico Brasileiro - de vínculos profundos com o imperador - e a sua Revista tornaram-se referências importantes para o desenvolvimento de diversas áreas do conhecimento científico no Brasil, entre as quais a de estudos da linguagem.

Algumas dessas sínteses sobre as configurações do debate no período são as seguintes:

$1 .^{\mathrm{a})}$ houve requisições de independência lingüística formuladas em diferentes graus. Isto é, houve desde propostas de autonomia lingüística plena, neste caso, considerando-se o português do Brasil como uma língua ou dialeto distinto daquele utilizado em Portugal, até propostas que vinculavam as diferenças lingüísticas constatadas apenas ao âmbito social; ou seja, que pressupunham que brasileiros cultos falariam como os lusitanos cultos, assim como os indivíduos pertencentes às classes populares, nos dois países, 
apresentariam "vícios" lingüísticos semelhantes. Havia ainda, é claro, aqueles que não reconheciam qualquer tipo de distinção entre os dois falares;

2. ${ }^{a}$ ) do ponto de vista dos dados selecionados para embasar as posturas mencionadas anteriormente, houve uma utilização mais larga dos lexicais e dos fonéticos, nesta ordem, e uma quase ausência de dados de outra natureza.

O privilégio conferido à palavra ia ao encontro de uma noção bastante difundida no período, que era a de "gênio" ou "índole" da língua. Essa noção corresponderia ao que há de essencial em cada sistema lingüístico. Durante o Segundo Reinado, o essencial parecia ser o léxico, entendido tanto num sentido constitutivo, mais próximo do que tomamos morfologia atualmente, quanto num sentido mais atrelado às significações, etimológicas ou correntes no período.

A sintaxe, via de regra, encontrava-se associada ao plano do estilo e não se prestava a ser um argumento suficiente nem para se diferenciar o português do Brasil do português de Portugal, nem para que eles fossem tomados como a mesma língua.

As citações abaixo exemplificam essas duas características do debate que explicitamos até aqui, isto é: a defesa de diferentes graus de autonomia lingüística para o português do Brasil e a utilização predominante do léxico como justificativa para os diferentes graus de autonomia propostos.

(C)

O português hodierno no Brasil (...) é o mesmo de Portugal, não obstante ir-se já diferenciando, principalmente na pronuncia.(...) Conta também o luso-americano algumas palavras que mudaram a significação.

Além disso, tem se opulentado o seu vocabulario com provincianismos e brazileirismos, ou seja palavras tupis: jacá, tabatinga; ou africanas: batuque, senzala; ou meramente populares: pelego, quindim.

As divergências syntacticas são em geral solecismos usados pelas classes incultas, como amo-lhe, vi elle, me disse (...) que vão desaparecendo com a reaç̧ão culta e litteraria, que trata de fazer approximar a linguagem das fontes vernaculas e classicas. (Paranhos da Silva, 1879) 
(D)

Muitas delas ["vozes" = palavras] são comuns a Portugal e ao Brasil; algumas lá ficaram, que nunca foram aqui aceitas; outras, que entre nós se aforaram jamais foram ouvidas em Portugal; outras, finalmente, que vieram de Portugal, passaram ou estão passando no Brasil pelas transformações dialetais que denunciam o progressivo desenvolvimento, de todas as línguas. Não será ousadia afirmar que na segunda metade do século XX o léxicon brasileiro não há de ser mais o léxicon português. (Soares, 1942, p. 72-73)

Essas duas características dizem respeito não só às obras com as quais lidamos, mas correspondem a idéias que circulavam no período, compondo o que chamamos tecnicamente de "clima de opinião intelectual" (Koerner, 1989).

O léxico configurava-se como argumento decisivo na diferenciação das estruturas lingüísticas e, na medida em que individualizava as línguas, era também decisivo para a constituição da nacionalidade, como vimos na citação (A), de Macedo Soares.

As citações $(\mathrm{E})$ e $(\mathrm{F})$, abaixo, tentam demonstrar que o grau de autonomia do português do Brasil era de fato um problema científico para aqueles estudiosos. Tanto assim que um mesmo autor pode oscilar, de momento a momento, em relação ao nível de independência que reivindica para a língua:

(E)

Já tivemos ocasião de explicar o sentido em que empregamos a expressão dialeto brasileiro. Em geral, falamos esse dialeto, mas procuramos escrever um português que às vezes não é entendido, porque... digamos com franqueza: o português de Portugal não é inteiramente a língua do Brasil, e é raro escrever bem não sendo na própria língua. (Soares, 1942, p. 81)

(F)

Temos muitas vezes, no correr deste escrito, falado em dialeto brasileiro. Cumpre observar que não apuramos o valor científico da palavra dialeto. Se entendemos por dialeto a linguagem derivada 
da língua geral de uma nação e particular a uma cidade ou província, o brasileiro não é dialeto do português. Por outro lado, a expressão língua brasileira nos parece demasiado pretensiosa, se se quer com ela distinguir o português falado no Brasil, modificado pelo clima, pela natureza ambiente, pela influência dos elementos africano e indiano, das relações comerciais, etc. do português falado em Portugal. Empregamos como mais modesta a outra expressão, que é ao mesmo tempo menos incorreta, e dá bem a entender que nos referimos ao movimento que visivelmente se está operando na linguagem nacional. (Soares, 1942, p. 73)

De acordo com o trecho (E), a língua por aqui já estaria diferenciada da portuguesa a ponto de a usarmos de outro modo; mas faltava registrar tais alterações na escrita, que se mantinha ainda naquela "outra língua". A diferença, portanto, é equacionada em termos de modalidades oral e escrita.

A escrita, e neste ponto procede a interpretação de Pinto (1978) de que haveria uma motivação literária para a contenda em torno da língua, poria o português do Brasil na categoria das línguas de civilização e o diferenciaria das "línguas rudes de África e Ásia" - ágrafas e, portanto, selvagens. A uma nação civilizada caberia uma língua com igual atributo. Daí a requisição de uma escrita brasileira, distinta da portuguesa.

No trecho (F), o mesmo autor apresenta uma outra proposta: afirma que a "linguagem nacional" não pode ser tomada como uma simples variante regional do português europeu; nesse sentido, não seria um dialeto. Mas, por outro lado, as modificações por que vinha passando ainda não autorizariam falar em "língua brasileira". A expressão "dialeto brasileiro", então, daria conta de que haveria um processo notável de diferenciação em curso. Como se tratasse de nações distintas, com climas, formação étnica, atividades distintas, era natural que o que se falasse em uma e outra se diferenciasse.

De fato, essa perspectiva naturalista era uma das justificativas para se requerer uma língua ou dialeto diferenciado no Brasil: assim como do latim provieram diferentes e múltiplas línguas e dialetos, pelo fato de ele ter-se expandido por lugares com realidades distintas, também do português europeu estaria derivando uma nova realidade lingüística.

Além dessas duas sínteses sobre o período em relação ao tratamento desse tema, uma terceira é possível. 
3. $\left.{ }^{a}\right)$ nas obras lexicográficas, as preferências e outras subjetividades dos autores afloram a todo momento.

É em função disso que o português do Brasil, via de regra, é apresentado como "melhor" que o de Portugal:

(G)

Mais dia, menos dia, [os críticos de Lisboa] vão ser forçados a fazer duas confissões importantes: a 1. ${ }^{a}$ é que no Brasil a língua portuguesa tem sido menos atacada do gálico, que a está corroendo e deformando em Portugal; a 2. é que temos uma língua nossa, e, portanto, uma literatura nossa... (Soares, 1942, p. 87)

Nesse excerto, o argumento para tomar o português do Brasil como melhor é a sua pureza, posto que ele estaria menos suscetível à incorporação de interferências externas que o português europeu.

Nos trechos abaixo, há um outro critério para a exaltação da nossa língua, o quantitativo. O português do Brasil seria mais rico, por compreender aquilo que havia no português de Portugal e (mais) as contribuições locais para o léxico nacional. $\mathrm{O}$ argumento é um dos mais recorrentes nessas obras.

(H)

Enquanto o sufixo eiro, eira no português de Portugal não é mais que a tradução do sufixo latino arius, aria, arium, no português do Brasil é isto e mais alguma coisa, é também a tradução do sufixo guarani êr de cuer, guer, puer, rer. Donde se conclue em favor da maior riqueza do dialeto brasileiro, e, sobretudo, da divergência, bem acentuada, já, que, ainda por este lado, vai affirmando a nossa nacionalidade, quer política, quer literária (Soares, 1942, sem grifos no original)

(I)

Tapera - uma das muitas palavras bonitas que possuímos e que se não acham no português de Portugal, guarani pura, formada 
de tab, povo, aldeia, habitação, fazenda, lugar, povoado, com o pret. Er, e a troca do b por p: povoação que foi e ora está deserta... (Soares, 1942, p. 109, sem grifos no original)

(J)

Atalhar, v. tr. (São Paulo, Minas-Geraes, Goyaz e mato-Grosso) concertar as cangalhas, de modo que não firam os animaes. É obrigação dos arrieiros ou arriadores. Obs. Há na língua portugueza o verbo atalhar com a significação de cortar, interromper, embaraçar, estorvar, impedir, encurtar o caminho, $e$ em todos estes sentidos é também usado no Brasil; mas, em relação ao serviço das cangalhas, é expressão exclusivamente brazileira. (Rohan, 1889, sem grifos no original)

Quando comparada à língua de Portugal, a do Brasil esteve sempre em vantagem: os autores enxergaram, por exemplo, corrupção da língua na alegada pronúncia desnaturada das vogais átonas em Portugal, enquanto alterações fonéticas ocorridas no Brasil foram percebidas como recuperação e preservação de traços do português antigo, genuíno. Na mesma medida, interferências do gálico no português de Portugal correspondiam a deturpação, enquanto as interferências indígenas e africanas redundavam em enriquecimento, e até em embelezamento, da língua no Brasil.

O "dialeto brasileiro", em vista dos predicados que lhe eram atribuídos, seria novo e resultante da miscigenação (etno)lingüística, mas também um guardião da tradição lingüística lusitana mais profunda e pura, já que avesso a galicismos e outros modismos lingüísticos abundantes em Portugal (Coelho, 2000).

Está claro, então, que, além dos critérios estritamente lingüísticos evocados para o estabelecimento da diferenciação entre o português do Brasil e o português europeu (doravante, $\mathrm{PB}$ e PE), havia os opinativos, que se construíam em torno de relações entre preservação/deturpação, riqueza/pobreza, doçura/ aspereza, beleza/fealdade, nas quais, invariavelmente, o pólo positivo aplicavase ao PB.

Ao lado dessas caracterizações opinativas, também algumas posturas em relação às palavras dicionarizadas, a seus referentes e ao seu tratamento descritivo marcam-se pelo caráter subjetivo, como nos casos a seguir: 
(L)

Arassá, s.m., fructa do arassazeiro, nome commum a diversas espécies de plantas do gênero Psidium, da família das Mytarceas. Etym. É vocábulo tupi. Geralmente se escreve Araçá, mas eu prefiro a orthographia que adoptei... (Rohan, 1889)

(M)

Alagadiceiro. adj. Boi alagadiceiro é o que come as hervagens e pastos alagadiços (Moraes). Este auctor não menciona a provincia em que é usual este vocábulo, e contenta-se em dizer que é termo do Brazil. Aulete não trata d'elle; e eu pela minha parte declaro que nunca o ouvi pronunciar. (Rohan, 1889)

$(\mathrm{N})$

Fulo adj. 1) cor de mulato escuro-avermelhado, preto-amarelado, como são os fulbê ou Fullas, pl. de Pulo, nação da África ocidental, situada entre o Senegal e o Niger, vizinhos dos mandingas; cabelos crespos, mas não lanzudos como os dos negros: cor parda clara, ou antes avermelhada; face ortognata; nariz pequeno, cartilaginoso e aquilino; cara agradável; mais inteligentes, e em geral de melhor caráter que os negros... (Soares, 1942, p. 120-121, sem grifos no original)

(O)

Sabinada - nome de uma revolta na província da Bahia, á testa da qual figurou um facinora por nome Sabino. (Rubim, 1853)

(P)

Ikrim - Serra em Guarapuava. É palavra came, e quer dizer cabeça. Os conhecem a serra melhor podem ajuizar da propriedade da expressão. Nisto eram os índios insignes: cada nome que davam a plantas, ou animais, ou lugares, era e é ainda perfeitamente justificado; procure-se, em caso de dúvida, e lá surge a etimologia em forma tão acabada, e engenhosa, e exata, que maravilha. (Soares, 1942, p. 189, sem grifos no original) 
Predileções políticas, raciais, regionais, como se vê, permeiam os textos. É altamente provável que elas possam ter determinado a própria escolha dos itens a serem dicionarizados, do mesmo modo que determinaram certas definições para eles elaboradas. O elogio e a ofensa às etnias que compunham a população do país ladeiam aprovações e reprimendas a grupos políticos, a moradores de certas regiões do país, a seguidores de dadas religiões, a determinadas expressões de cultura ou arte e até grafias. A subjetividade integra, de forma explícita, o método de constituição do saber lingüístico em foco.

Uma quarta síntese possível a partir da análise desse material, além das precedentes, é a de que essas fontes, utilizadas neste texto com a finalidade de reconstrução histórica de um problema lingüístico específico, prestam-se também ao papel de instrumentos válidos para o conhecimento sobre essa língua ou variante num dado recorte temporal.

Podemos saber mais sobre o PB da segunda metade do século XIX, sobre seus contrastes e semelhanças com o PE, assim como sobre as variantes regionais brasileiras. É claro que, sempre, pelo viés dos autores estudados. Daí a não possibilidade de tomar esses e outros "produtos" simplesmente como dados de língua. Eles são, necessariamente, representações subjetivas desses dados, cuja fidedignidade cabe investigar.

As citações de (Q) a (S) exemplificam essas formas de representação. Os dados lexicais estão em maior número, dada a concepção da época sobre o papel do léxico, mas também foram selecionadas referências à sintaxe:

(Q)

Dizem os portugueses "estar ao sol, à chuva, ao sereno"; nós dizemos "no sol, na sombra, no claro, no escuro, no fundo, no raso, na chuva, no sereno", como dizemos "no mato, no campo, em terra, no mar". (Soares, 1942, p. 55)

(R)

Axi!, int. (Pará) expressão de tédio ou repugnância para com alguma cousa ou dito desagradável (B. de Jary). Correspondente ao portuguez apre! Fóra! Também dizem Exe! (Rohan, 1889) 
(S)

Bála, s.f. (R. de Jan. e Provs. Merid.) pequena pelota de assucar refinado em ponto vítreo e envolta em papel. É o que em Portugal e no Pará chamam rebuçado; na Bahia, queimado; em Pernambuco, Alagoas e outras províncias do Norte, Bola. Etym. Este confeito deve, sem dúvida, à forma arredondada que lhe davam antigamente. Hoje há balas de todos os feitios. (Rohan, 1889)

Em vista dos dados que expusemos ao longo deste texto, é possível afirmar que, no período, houve um debate relevante sobre o estatuto do português do Brasil e que os dados lingüísticos aos quais recorremos nesse debate foram majoritariamente os lexicais, considerado o papel central atribuído ao léxico no período.

Podemos afirmar também que, ao tratar desse tema, estudiosos da época, construíram cenário rico em informações lingüísticas e em idéias correntes no período, tais como as referentes a etnias e à linguagem utilizada na ex-metrópole.

Podemos afirmar, ainda, que havia um clima de opinião favorável a teses nacionalistas em geral e a teses de nacionalismo lingüístico em particular durante o Segundo Reinado.

No entanto, o que constatamos é que as idéias de autonomia do português do Brasil defendidas no período não vingaram e tais trabalhos desfrutaram de pouca repercussão.

\section{Em busca de hipóteses explicativas}

Uma hipótese explicativa possível para tal destino, do ponto de vista do método, parece situar-se na própria escolha do nível lexical como o principal fornecedor de argumentos, conjugada às formas de descrição efetuadas. Ao buscar a diferenciação e a autonomia em estruturas mais movediças e permeáveis a interferências externas, e tratá-las ao sabor de preferências individuais, os dicionaristas teriam comprometido a defesa da tese de existência de uma língua brasileira.

Essa é uma hipótese explicativa construída com base em dados referentes aos métodos e em alguns outros referentes aos contextos político e intelectual. Ela soa plausível e pode sustentar "uma" interpretação historiográfica do conhecimento lingüístico em foco. 
Intencionalmente, muitos dos elementos que compunham o cenário do qual nos aproximamos, como os referentes às biografias dos autores, foram aqui descartados ou não ganharam destaque. A seleção efetuada visou à demonstração de que, mais do que a exaustividade descritiva, a determinação de aspectos decisivos e a demonstração de suas correlações são essenciais ao trabalho historiográfico. Sobretudo quando entendemos que a historiografia não é uma mera coleta de informações sobre o passado, mas uma disciplina que permite encontrar vias interpretativas para a história e, por meio delas, tecer reflexões relevantes para a condução do próprio fazer lingüístico contemporâneo.

\title{
RESUMO
}

Este texto exemplifica como os períodos e contextos da história do conhecimento científico podem ser examinados pela perspectiva da Historiografia da Lingüística. Seu objetivo é demonstrar que o historiógrafo, ao lidar com qualquer tema dessa área, deve fornecer uma verdadeira teia explicativa dos fatos. O tema abordado é o da reivindicação de autonomia para o português do Brasil em dicionários produzidos durante a segunda metade do século XIX. Propomos que aspectos referentes aos métodos empregados nessas descrições do léxico brasileiro teriam dificultado a aceitação da reivindicação no período, embora o contexto fosse altamente favorável para sustentá-la.

Palavras-chave: Historiografia da lingüistica, contextos, métodos, lexicografia, lingua brasileira.

\begin{abstract}
This paper exemplifies how periods and contexts into the history of scientific knowledge can be examined through the perspective of Linguistic Historiography. Its aim is demonstrate that an explanatory web of facts must be provided by the historiographer when he works with any issue in that area. The issue in focus is the claim of autonomy to Brazilian Portuguese in certain dictionaries that was produced in the second half of the $19^{\text {th }}$ century. According to our hypothesis, some aspects related to the methods applied in those Brazilian lexis descriptions would make the acceptance of that claim difficult in the period, although the context was auspicious to support it.

Key-words: Linguistic historiography, contexts, methods, lexicography, Brazilian language.
\end{abstract}




\section{REFERÊNCIAS}

COELHO, Olga. Vocabulario brazileiro: motivação e arbitrariedade na codificação do português do Brasil (1850-1890). São Paulo: Cedoch-DL/USP/Capes, 2000. Projeto de doutorado integrado ao projeto coletivo "Nossa língua e essoutras: uma historiografia da diversidade lingüistica", coordenado por Cristina Altman.

KOERNER, E.F.K. Practicing Linguistic Historiography. Amsterdam: John Benjamins, 1989.

PARANHOS DA SILVA, José Jorge. O idioma do hodierno Portugal comparado com o do Brasil. Rio de Janeiro: L. Winte, 1879/1880.

PINTO, Edith Pimentel. O português do Brasil. Textos críticos e teóricos. Fontes para a teoria e a história (1820-1920). Rio de Janeiro: Livros Técnicos e Científicos, 1978. v. 1.

ROHAN, Henrique de Beaurepaire. Diccionario de vocabulos brazileiros. Rio de Janeiro: Imprensa Nacional, 1889.

RUBIM, Braz da Costa. Vocabulario brazileiro (para servir de complemento aos diccionarios da lingua portugueza). Rio de Janeiro: Empresa Typographica Dous de Dezembro, de Paula Brito, 1853.

SOARES, Antônio Joaquim de Macedo Soares. Estudos lexicográficos do dialeto brasileiro. 2. ed. Rio de Janeiro: Publicação da Revista do Instituto Histórico e Geográfico Brasileiro, 1942 [1874-1890].

. Dicionário brasileiro da língua portuguesa. 2. ed. Rio de Janeiro: Instituto Nacional do Livro, 1954 [1875-1888].

SCHWARCZ, Lília Moritz. As barbas do imperador. D. Pedro II, um monarca nos trópicos. São Paulo: Cia. das Letras, 1999. 3. 'reimpressão.

SWIGGERS, Pierre. Reflections on (models for) Linguistic Historiography. In: HÜLLEN, W. (Ed.). Understanding the historiography of linguistics. Münster: Nodus, 1990. p. 2134. 